\title{
PERANCANGAN SISTEM INFORMASI MONITORING KEGIATAN POSYANDU PARAKANSALAK SUKABUMI
}

\author{
Reza Rizki Fauzi \\ Universitas Indraprasta PGRI \\ Jalan Raya Tengah, Gedong, Pasar Rebo, Jakarta Timur, Daerah Khusus Ibukota Jakarta 13760 \\ rezarizki1511@gmail.com
}

\begin{abstract}
ABSTRAK
Dalam kegiatan posyandu saat ini masih menggunakan metode catatan, Terutama dari data-data kegiatan posyandu seperti pendaftaran yang setiap bulanya akan mengalami peningkatan ataupun penurunan. Dalam era perkembangan teknologi yang pesat, Hal ini sangat kurang efesien. Untuk menunjang kelancaran aktivitas maka dibutuhkanlah sistem informasi terkomputerisasi. Maka penelitian ini bertujuan untuk membuat perancangan sistem informasi posyandu parakansalak sukabumi dengan metode penelitian yang dilakukan dengan cara observasi dan wawancara untuk mengetahui informasi dengan cara pengamatan segala kegiatan secara langsung serta menanyakan kepada narasumber yang terlibat. Nantinya sistem informasi posyandu ini dapat membantu kader posyandu dalam melaksanakan kegiatan, Mengolah data posyandu, Monitoring data kesehatan ibu bayi dan anak, Chart diagram untuk melihat pertumbuhan kembang anak serta laporan yang lebih cepat dan efektif.
\end{abstract}

Kata Kunci: Sistem, Informasi, Monitoring, Posyandu

\begin{abstract}
In posyandu activities at this time, they still use the record method, especially from data on posyandu activities such as registration which every month will increase or decrease. In the era of rapid technological development, It is very less efficient. To support the smooth running of activities, a computerized information system is needed. So this study aims to design an information system for Posyandu Parakansalak Sukabumi with research methods carried out by observation and interviews to find out information by observing all activities directly and asking the sources involved. Later this posyandu information system can assist posyandu cadres in carrying out activities, processing posyandu data, monitoring maternal and child health data, chart diagrams to see child development and faster and more effective reports.
\end{abstract}

Key Word: System, Information, Monitoring, Posyandu

\section{PENDAHULUAN}

Posyandu merupakan bentuk upaya kesehatan bersumber daya masyarakat, hak milik masya rakat, serta menyatu dalam kehidupan ataupun budaya yang dilaksanakan oleh, dari serta bersama masyarakat guna dalam kemudahan terhadap masyarakat untuk memperoleh pelayanan kesehatan ibu bayi ataupun anak. (Kementerian Kesehatan Republik Indonesia, 2011).

Dalam melaksanakan aktifitas posyandu terdapat suatu kegiatan yang meliputi pendaftaran, pemeriksaan ibu hamil, penimbangan imunisasi dan kb. Dalam kegiatan tersebut dibutuhkan perancangan sistem informasi posyandu parakansalak sukabumi untuk membantu kader dalam melaksanakan pelayanan posyandu serta hasil laporan data setiap bulanya. Karena apabila masih dalam metode tulis tangan secara manual akan kurang efesien, Data tidak tersusun dengan baik dan kemungkinan besar terjadinya hilang atau rusak, Pencarian data membutuhkan waktu yang lama serta dapat menimbulkan kesalahan dalam pengecekan data karena penumpukan arsip data yang semakin banyak. Dengan ini diperlukanlah mendesain aplikasi sistem perancangan informasi posyandu. (Ladjamudin, 2011) Sistem merupakan kumpulan kompenenkomponen yang membentuk satu kesatuan un tuk mencapai tujuan tertentu. (Tyoso, 2016). Pendataan adalah kumpulan angka atau karakter yang tidak memiliki arti. (Asropudin, 2013) Perancangan sistem informasi posyandu parakansalak sukabumi ini menggunakan perangkat lunak pendukung yaitu netbeans dengan bahasa pemrograman java dan database. Netbeans merupakan suatu editor untuk membuat aplikasi java yang di dukung dengan fitur komponen drag and drop. (Miftakhul Huda \& Bunafit Komputer, 2010). 
Java adalah sebuah bahasa pemrograman yang dipergunakan dalam pembuatan aplikasi berbasis handphone serta dapat menyediakan akses objek yang disisipkan pada aplikasi.(Sa llaby et al., 2015).

Dengan adanya Sistem terdapat manfaatnya yaitu untuk membantu petugas kader dalam melaksanakan, mengelola hingga memonitoring kesehatan ibu hamil dan anak beserta dengan data pelayanan hingga proses cetak laporan. Hasil penelitian ini dapat membantu meningkatkan efektifitas pekerjaan posyandu dalam mengolah datadata yang dilakukan kader, bidan atau kepala puskesmas dalam mengontrol dan mengawasi setiap data anak dalam bentuk statistik kesehatan ataupun data yang masuk maupun keluar yang telah terkomputerisasi di dalam sistem.

\section{METODE PENELITIAN}

Desain penelitian yang digunakan yaitu metode prototype, Karena pengembang dapat saling berinteraksi selama proses pembuatan sistem serta lebih memudahkan dalam proses desain dan memperbaiki user interface. Selain itu dengan metode ini, pengguna dapat berperan aktif dalam pengembangan sistem. (Kadir, 2014). Adapun rancanganya menggunakan mekanisme pengembangan sistem yang meliputi:

\section{Analisis}

Analasis kebutuhan dengan cara diskusi untuk menjelaskan sistem yang diusulkan.

2. Perancangan

Penyusunan rancangan dari hasil analisis dan kegiatan.

3. Pengembangan

Melakukan penyusanan dan validasi agar sesuai dengan perancangan sistem.

4. Umpan Balik

Tahap evaluasi terhadap hasil protype yang telah dirancang.

Selanjutnya ruang lingkup dari aplikasi perancangan sistem informasi posyandu yaitu mengenai perancangan dan implementasi pendataan yang manual kedalam sistem yang terkomputerisasi menggunakan bahasa pemrograman java netbeans. Kemudian untuk tempat penelitian penulis memilih untuk melakukan pengamatan langsung ke lokasi pada tanggal 4 Mei 2021 untuk tahap pertama yang dimana kami menanyakan perihal dari latar belakang, proses alur kegiatan, dan
Permasalahan yang di alami saat proses kegiatan posyandu berlangsung yang berada di salah satu dari ke sebelas posyandu yaitu posyandu anggrek yang berlokasi di kp cikupa kecamatan parakansalak, desa parakansalak, kota sukabumi. Kemudian melanjutkan kembali untuk melakukan penelitian tahap ke dua pada tanggal 8 Mei 2021 untuk mendapatkan informasi lebih terkait posyandu parakansalak tersebut dengan membaca buku dengan judul "Buku Panduan Kader Posyandu" yang di buat oleh kementrian kesehatan repubik indonesia tahun 2011 di lokasi dari ketua posyandu terkait yang terletak di desa kp pajagan desa parakansalak kabupaten sukabumi, kota sukabumi.

Teknik pengumpulan data yang di lakukan peneliti dalam membuat aplikasi sistem informasi posyandu ini menggunakan sumber data primer dan sumber data sekunder:

1. Sumber Data Primer

Proses ini terdiri dari (dua) 2 cara yakni observasi dan wawancara. Observasi yang dimaksud dengan pengamatan terhadap aspek kegiatan secara langsung dilapangan dan mencatat hal-hal apa saja yang penting serta menguraikan setiap proses yang terjadi setiap harinya. Sedangkan wawancara dilakukan dengan cara menanyakan langsung kepada narasumber yang terlibat di dalam proses yakni ketua posyandu, kader, dan orang tua yang sedang melakukan kegiatan.

2. Sumber Data Sekunder

Data sekunder didapat dalam mempelajari data-data yang diberikan pihak posyandu kepada penulis berupa dokumen ataupun arsip yang telah disediakan. Sumber data ini bertujuan untuk mengetahui hal-hal mengenai sejarah dan latar belakang pendirian posyandu terkait, Dokumen yang digunakan, proses kegiatan dan struktur organisasi. Dokumen-dokumen tersebut antara lain data ibu hamil, data anak, data imunisasi anak, penimbangan anak, pemeriksaan dan $\mathrm{kb}$.

Menurut (Yasin, 2011) menyimpulkan bahwa, UML (Unified Modeling Languag e) adalah bahasa permodelan untuk sistem perangkat lunak berorientasi objek. Berikut Teknik analisis penelitian ini menggunakan rancangan unified modeling language yang terdiri meliputi:

1. Use Case Diagram merupakan suatu rangkaian tindakan sistem. 
Aktor dimaksud menjadi perwakilan user atau sistem lain yang berinteraksi pada sistem yang telah dimodelkan. (Satzinger J, Jackson R, 2011)

2. Activity Diagram atau diagram aktifitas menggambarkan work flow (aliran kerja) aktivitas suatu sistem. (Dewi et al., 2017)

3. Sequence Diagram menggambarkan waktu aktif objek atau komponenkomponen dalam pengembangan sistem. (Nurdam, 2014)

4. Class Diagram atau diagram kelas menggambarkan kelas-kelas serta atribut yang saling berhubungan. (Romzah et al., 2021)

5. Spesifikasi File Basis Data data dapat membantu pengolahan dalam pembuatan pemprogram dalam menerjemahkan sistem ke dalam user interface agar sesuai dengan ketentuan inputan data yang diinginkan sistem agar lebih efektif dan efisien dalam pengelolaan data. (Fathansyah, 2012)

\section{HASIL DAN PEMBAHASAN}

Langkah-langkah perancangan sistem yang diusulkan:

Use Case Diagram

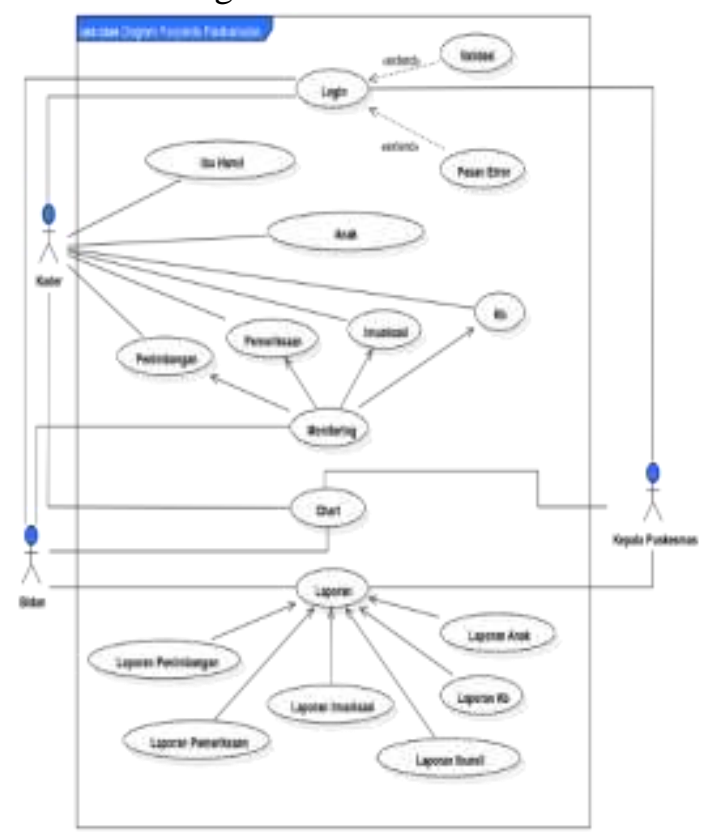

Gambar 1. Use Case Diagram

Pada gambar 1 terdapat 3 aktor yaitu kader, bidan dan kepala puskesmas yang mempunyai hak akses dan tugasnya masing-masing.
Activity Diagram

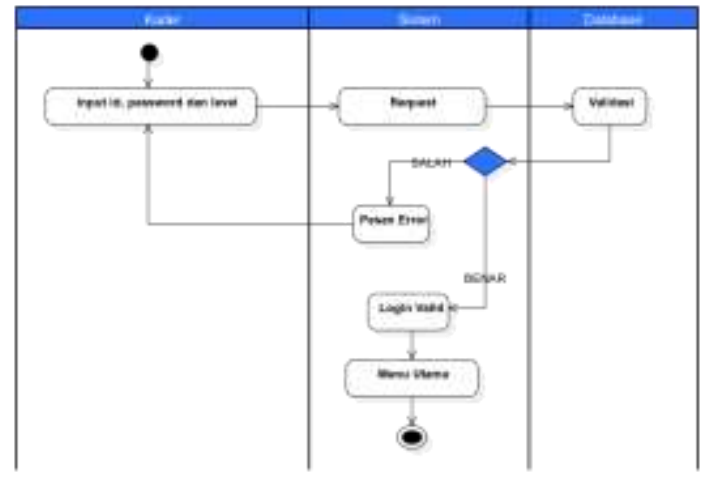

Gambar 2. Activity Diagram Login

Aktifitas Diagram login yang terdapat pada gambar 2 adalah alur aktifitas proses sebelum masuk ke dalam sistem, Tahap ini user harus input id, password dan level hak aksesnya untuk masuk kedalam sistem.

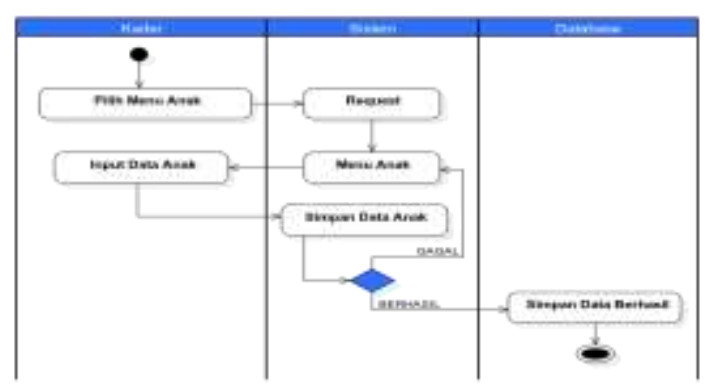

Gambar 3. Activity Diagram Anak

Diagram aktifitas anak yaitu proses input data anak yang melakukan pendaftaran, Data valid akan tersimpan ke database serta data tidak valid akan muncul pesan error pada sistem.

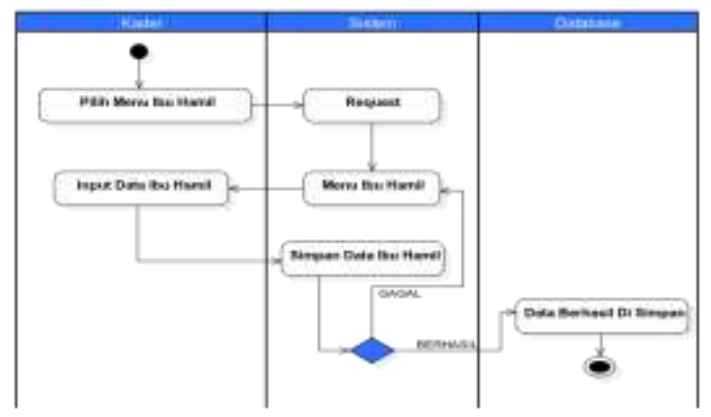

Gambar 4. Activity Diagram Ibu Hamil

Diagram aktivitas ibu hamil yaitu proses input data pendaftaran ibu ke dalam sistem. 


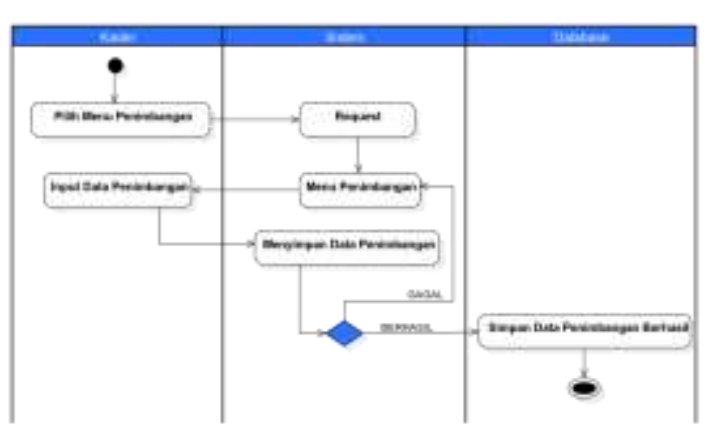

Gambar 5. Activity Diagram Penimbangan

Diagram aktifitas pada gambar di atas yaitu aliran proses kegiatan penimbangan bayi atau balita.

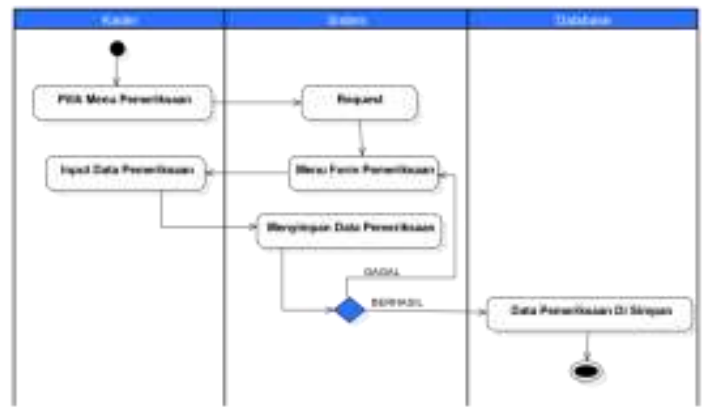

Gambar 6. Activity Diagram Pemeriksaan

Gambar diagram aktifitas diatas menampilkan aliran proses menyimpan data kegiatan pemeriksaan ibu hamil.

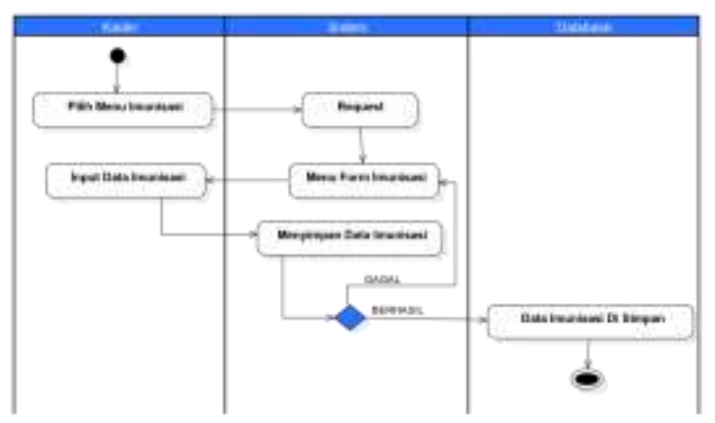

Gambar 7. Activity Diagram Imunisasi

Aktifitas imunisasi pada gambar 7 diatas adalah aliran proses imunisasi untuk anak serta menginput data hasil kegiatanya.

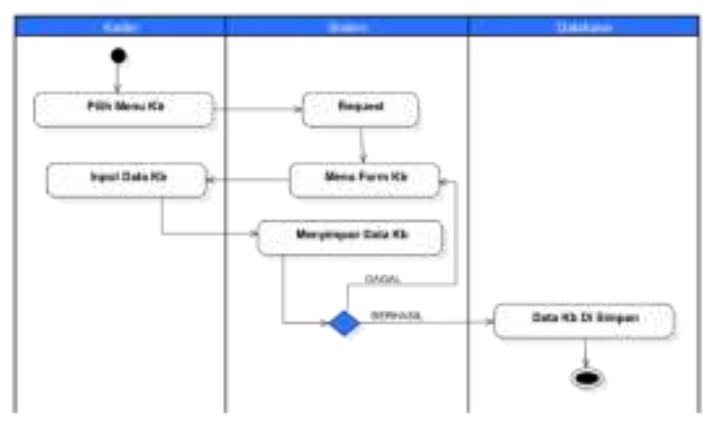

Gambar 8. Activity Diagram Kb
Diagram aktifitas $\mathrm{kb}$ menampilkan proses aliran dari kegiatan yang di laksanakan.

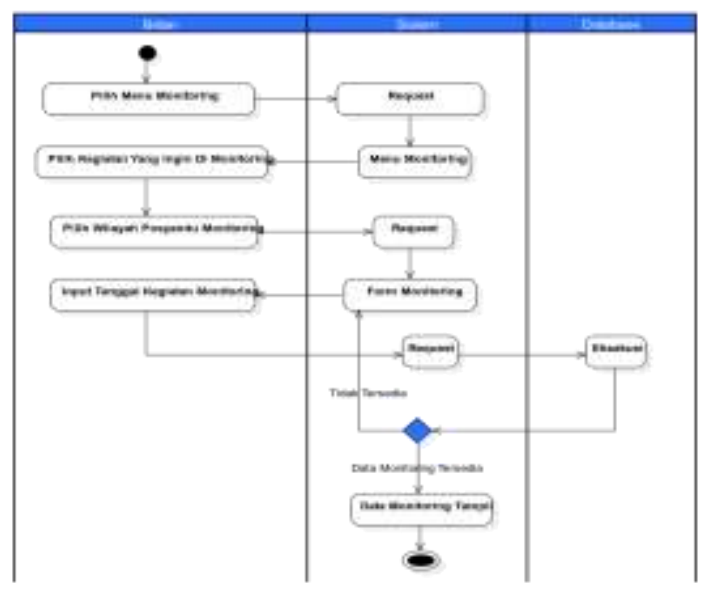

Gambar 9. Activity Diagram Monitoring

Diagram aktifitas monitoring adalah aliran proses untuk memonitoring data-data kegiatan hingga data kesehatan ibu bayi dan anak balita.

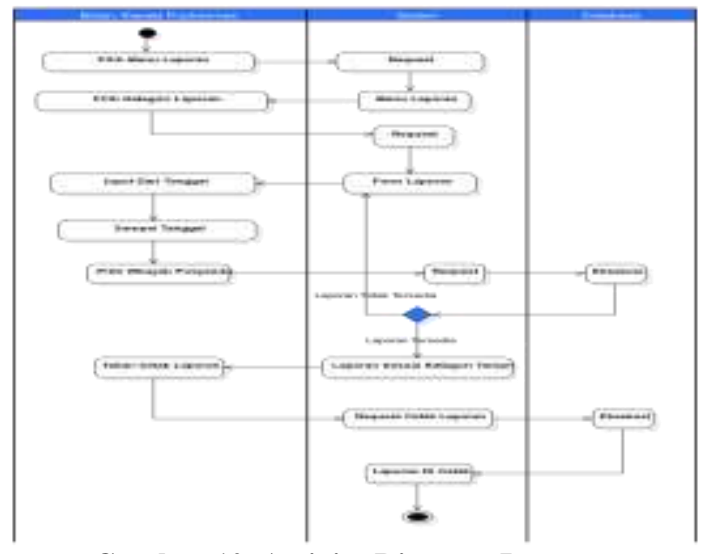

Gambar 10. Activity Diagram Laporan

Aliran aktifitas laporan diatas menampilkan proses cetak laporan dari hasil seluruh kegiatan yang terkait.

Class Diagram

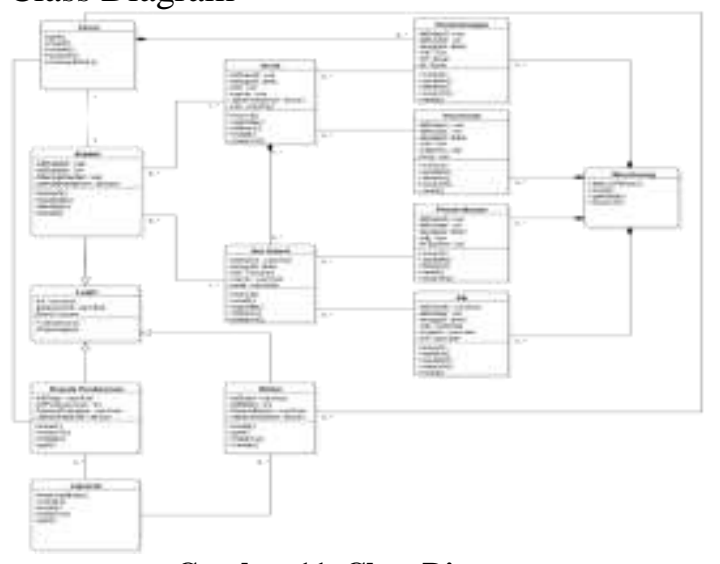

Gambar 11. Class Diagram

804 | Perancangan Sistem Informasi Monitoring Kegiatan Posyandu Parakansalak Sukabumi 
Pada gambar 11 terdapat kelas login, kader, ibu hamil dan lain-lain yang menggambarkan pendefinisian suatu kelas untuk membangun sistem informasi posyandu beserta dengan atributnya.

Tampilan Login

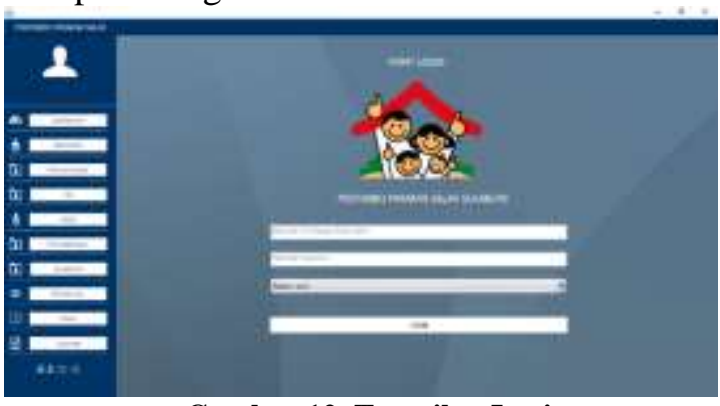

Gambar 12. Tampilan Login

Input id, password dan level kemudian klik button login.

Tampilan Menu Utama

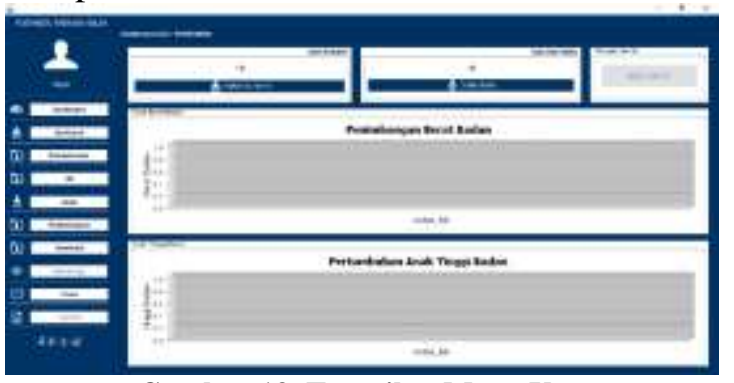

Gambar 13. Tampilan Menu Utama

Setelah login berhasil, Menu utama tampil, Kemudian dapat menekan tombol ibu hamil, pemeriksaan, $\mathrm{kb}$, anak, penimbangan, imunisasi

Tampilan Ibu Hamil

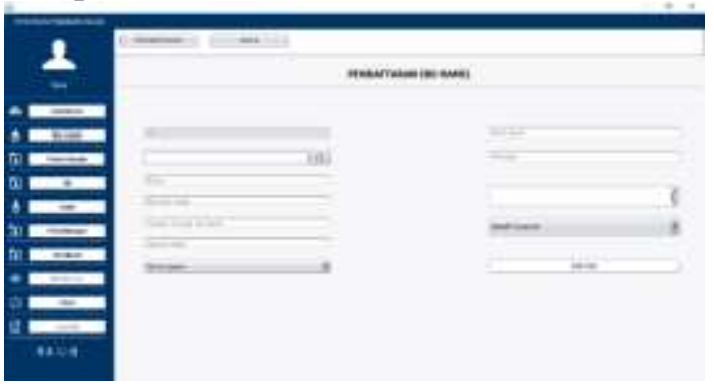

Gambar 14. Tampilan Ibu Hamil

Tampilan layar ini untuk pendaftaran ibu hamil dan tombol data ibu hamil.

Tampilan Pemeriksaan

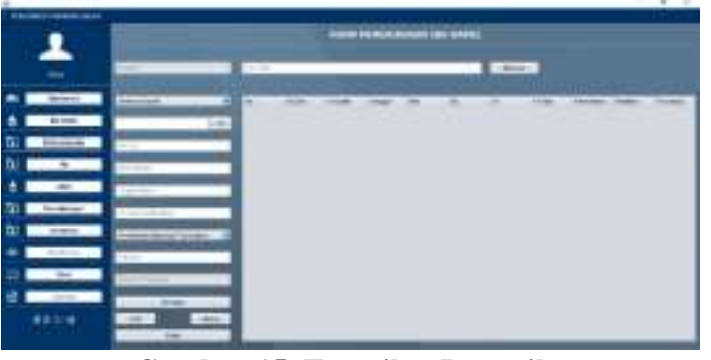

Gambar 15. Tampilan Pemeriksaan

Tampilan layar ini menampilkan form pemeriksaan untuk ibu hamil.

Tampilan $\mathrm{Kb}$

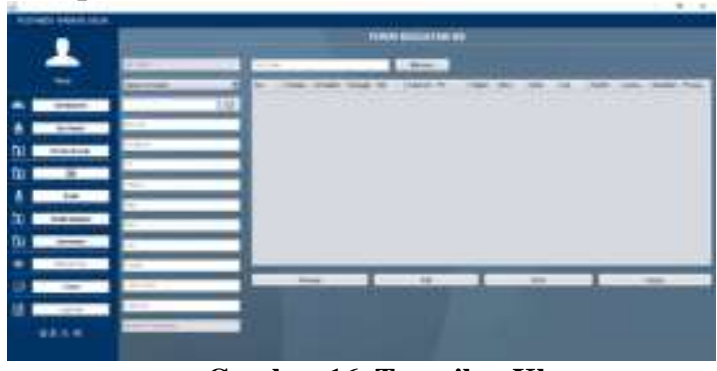

Gambar 16. Tampilan Kb

Tampilan layar ini menampilkan form $\mathrm{kb}$ ibu setelah melewati fase kehamilanya.

Tampilan Anak

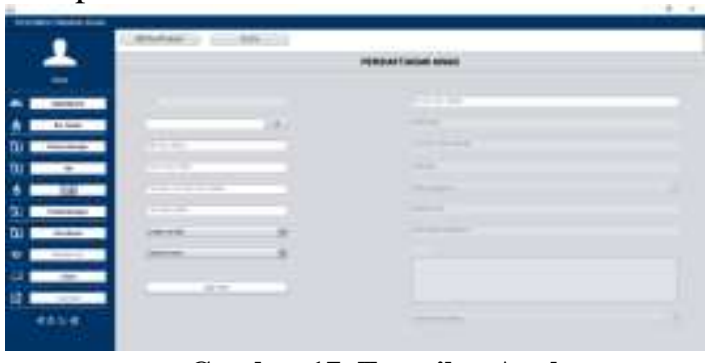

\section{Gambar 17. Tampilan Anak}

Tampilan Layar ini menampilkan form pendaftaran anak, Serta button data untuk menampilkan data anak yang terdaftar.

Tampilan Penimbangan

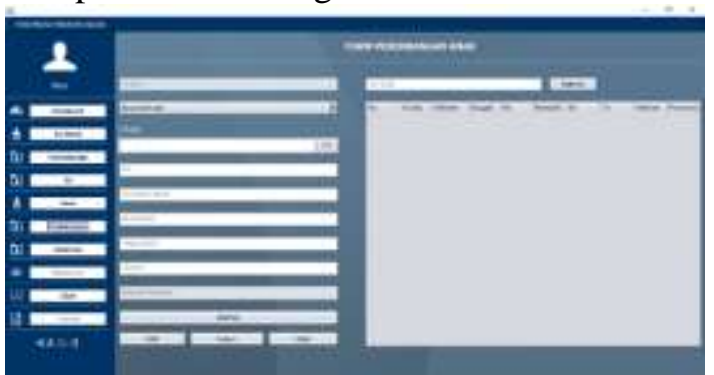

Gambar 18. Tampilan Penimbangan

Tampilan layar ini menampilkan form penimbangan anak. 
Tampilan Imunisasi

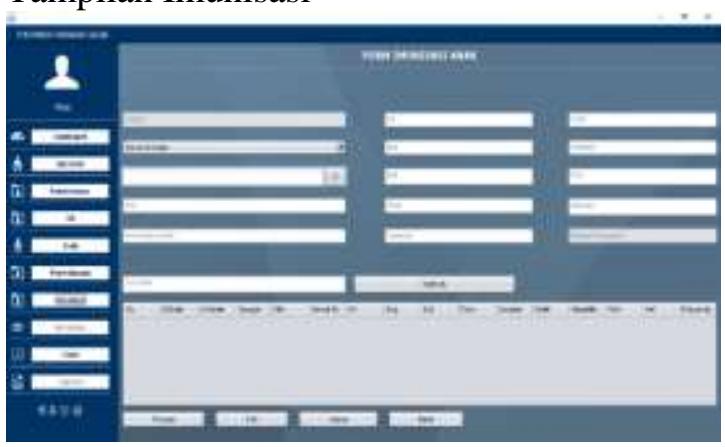

Gambar 19. Tampilan Imunisasi

Tampilan layar ini menampilkan form kegiatan imunisasi anak beserta dengan datanya.

Tampilan Laporan Ibu Hamil
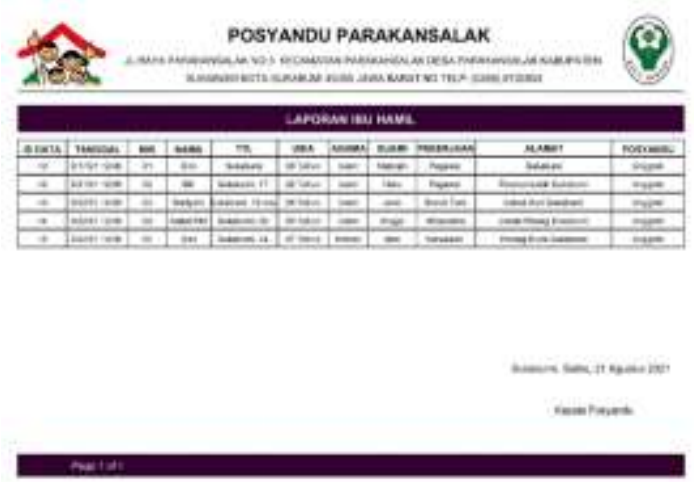

Gambar 20. Tampilan Laporan Ibu Hamil

Tampilan layar ini menampilkan hasil laporan dari pendaftaran ibu hamil.

Tampilan Laporan Pemeriksaan

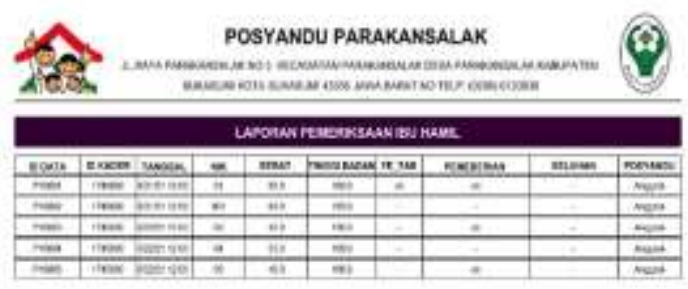

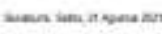

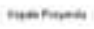

Gambar 21. Tampilan Laporan Pemeriksaan

Menampilkan hasil laporan pemeriksaan dari kegiatan pemeriksaan ibu hamil.
Tampilan Laporan $\mathrm{Kb}$

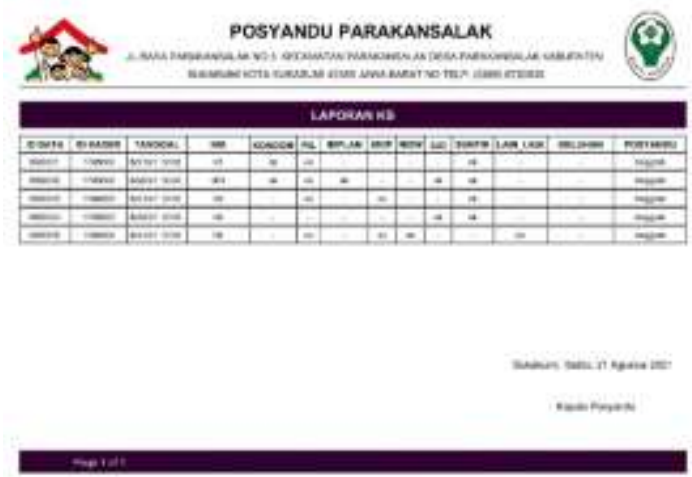

Gambar 22. Tampilan Laporan Kb

Menampilkan hasil laporan $\mathrm{kb}$ dari pelayanan terkait.

Tampilan Laporan Anak

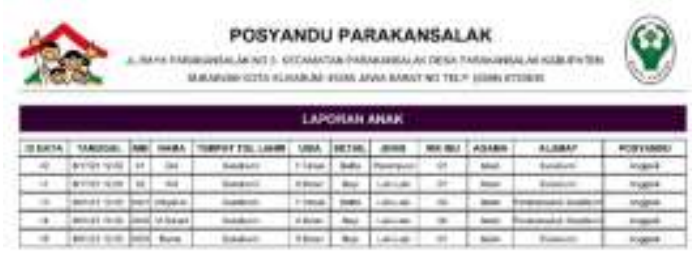

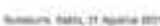
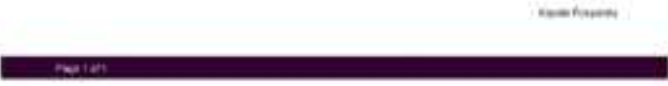

Gambar 23. Tampilan Laporan Anak

Tampilan layar ini menampilkan hasil laporan pendaftaran anak.

Tampilan Laporan Penimbangan
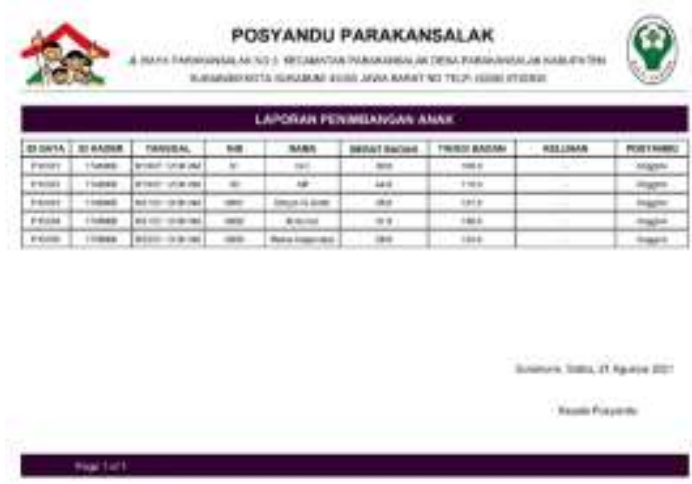

Gambar 24. Tampilan Laporan Penimbangan

Tampilan ini menmapilkan hasil laporan penimbangan bayi atau balita yang telah melakukan pelayanan penimbangan. 
Tampilan Laporan Imunisasi

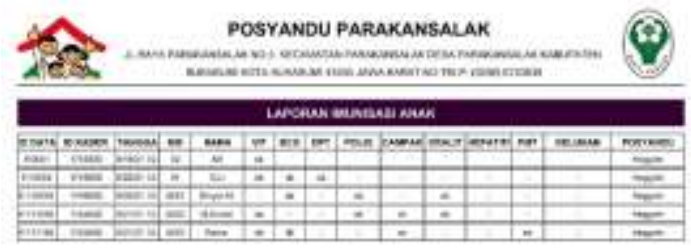

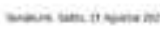

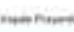

Gambar 25. Tampilan Laporan Imunisasi

Menampilkan hasil laporan imunisasi dari bayi ataupun balita yang telah melakukan pelayanan imunisasi.

\section{SIMPULAN DAN SARAN}

Hasil uraian dan pembahasan pada bab-bab yang telah di buat sebelumnya, Maka peneliti mengambil simpulan bahwa penelitian ini menghasilkan sistem informasi posyandu yang mendukung kesehatan ibu dan memonitoring tumbuh kembang bayi. Sistem memiliki detail sebagai berikut:

Sistem informasi posyandu parakansalak sukabumi berbasis desktop, Sehingga penyimpanan dan pencarian data terkait ibu dan anak dapat di akses dengan mudah.

Sistem informasi posyandu memliki fitur-fitur yang dapat membantu petugas posyandu dalam mengelola data ibu dan anak, Kemudian fitur monitoring dapat membantu bidan yang bertugas, Selanjutnya fitur laporan dan chart diagram juga dapat membantu kepala puskesmas untuk melihat tumbuh kembang bayi beserta dengan data-data laporan yang lebih efektif.

Adapun saran berdasarkan simpulan dan analisis yang dikemukakan, Sistem yang dibangun masih terdapat keterbatasan dan kekurangan serta memerlukan perbaikan untuk meningkatkan manfaat dari sistem ini yang dapat dikembangkan pada penelitian selanjutnya yaitu sebagai berikut:

Sistem informasi posyandu yang dibangun dapat di kembangkan berbasis web atau mobile. Sistem informasi posyandu dikembangkan dalam ruang lingkup yang lebih besar, Tidak hanya pada tingkat posyandu parakansalak sukabumi.
DAFTAR PUSTAKA

Asropudin, P. (2013). Kamus Teknologi Informasi. In Kamus Teknologi Informasi. Titian Ilmu.

Dewi, L. P., Indahyanti, U., \& S, Y. H. (2017). Pemodelan Proses Bisnis Menggunakan Activity Diagram Uml Dan Bpmn ( Studi Kasus Frs Online ). Informatika, $1-9$.

Fathansyah. (2012). Basis Data. Informatika Bandung.

Kadir, A. (2014). Pengenalan Sistem Informasi (H.Dewi (ed.)). Penerbit Andi.

Kementerian Kesehatan Republik Indonesia. (2011). Pedoman Umum Pengelolaan Posyandu. Kementerian Kesehatan RI.

Ladjamudin, B. A. B. (2011). Analisis dan Desain Informasi. Alfabeta. Andi, Yogyakarta

Miftakhul Huda \& Bunafit Komputer. (2010). Membuat aplikasi Rental Dengan Java dan MySQL. PT Elex Media Komputindo.

Nurdam, N. (2014). Sequence Diagram Sebagai Perkakas Perancangan Antarmuka Pemakai. Jurnal ULTIMATICS, 6(1), 21-25.

Romzah, R., Wibawa, Y. E., \& Larasati, P. D. (2021). Pembangunan Sistem Informasi Kartu menuju Sehat (KMS) Balita Berbasis WEB Studi Kasus: Posyandu Kasih Bunda II. Jurnal SISKOM-KB (Sistem Komputer Dan Kecerdasan Buatan), 4(2), 75-81.

Sallaby, A. F., Utami, F. H., \& Arliando, Y. (2015). Aplikasi Widget Berbasis Java. Jurnal Media Infotama, 11(2), 171-180.

Satzinger J, Jackson R, B. S. (2011). Introduction to Systems Analysis and Design. Course Technology.

Tyoso, J. S. P. (2016). Sistem Informasi Manajemen. Deepublish.

Yasin, verdi. (2011). Rekayasa Perangkat Lunak Berorientasi Objek. In Verdi Yasin, S.Kom.,M.Kom. Penerbit Andi. 